Rev. Saúde públ., S. Paulo

2(2) :95-110, dez. 1968

\title{
Editorial
}

\section{APRECIAÇÃO DO "PLANO NACIONAL DE SAÚDE" (1)}

Ante a divulgação, pela imprensa, de notícias sôbre a elaboração de um nôvo Plano Nacional de Saúde, a Faculdade de Higiene e Saúde Pública da Universidade de São Paulo, dada a transcendental importância do assunto, deliberou tomar conhecimento do anteprojeto e, através de seus técnicos, examinar os seus fundamentos e conteúdo, a fim de opinar sôbre o acêrto das diretrizes e ações propostas, bem como sôbre a exeqüibilidade do programa.

Neste documento serão abordados, sucessivamente, os aspetos doutrinários, econômicos, financeiros, administrativos e metodológicos do mencionado Plano.

\section{1 - ASPETOS DOUTRINARIOS}

A saúde é fundamentalmente um problema de definição social, cabendo a cada sociedade, em determinada situação, não apenas definí-la, mas apresentar as soluções compatíveis.

Êste é o dado objetivo, a partir do qual os técnicos procurarão determinar o nível de saúde de uma comunidade, julgar seu grau de satisfatoriedade, medir suas deficiências e programar não só o atendimento destas como criar condições para a passagem a um estágio superior.

Está indiscutivelmente "estabelecido que a saúde é um dos componentes do desenvolvimento econômico e do progresso so- cial e, conseqüentemente, uma responsabilidade governamental inalienável. A Declaração dos Princípios da Carta da Organização Mundial da Saúde estabelece que "o gôzo do máximo grau de saúde que se pode lograr é um dos direitos fundamentais de todo ser humano, sem distinção de raça, religião, ideologia política e condição econômica ou social"; e acrescenta, mais adiante, que "os governos têm responsabilidade na saúde de seus povos".

Inspirados nos mesmos conceitos básicos, estadistas e técnicos em saúde, sob os auspícios das organizações internacionais, definiram de modo claro e em têrmos concordantes, os princípios doutrinários que têm servido de base ao planejamento das ações médico-sanitárias dos países. A Carta do Atlântico, a Recomendação 69 da 26 Conferência Interamericana do Trabalho, a Constituição da O.E.A., a Operação Panamericana, a Ata de Bogotá e, finalmente, a Carta de Punta del Este, são alguns dos documentos, todos assinados ou referendados pelo Govêrno Brasileiro, que, em conjunto, estabeleceram as linhas mestras para a formulação de uma política de saúde coerente com o progresso social e baseada nos avanços técnico-científicos da época atual.

Em abril de 1963, os ministros da saúde dos países americanos, reunidos em Washington, sob o patrocínio da Organização Panamericana da Saúde e da Organização dos Estados Americanos, concluiram "ser indispensável que os Ministérios

(1) Trabalho elaborado por um grupo de docentes da Faculdade de Higiene e Saúde Pública da USP e aprovado pela Congregação em reunião realizada a 28-6-1968. 
EDITORIAL - Apreciação do "plano nacional de saúde. Rev. Saúde públ., S. Paulo, 2(2): 95-110, dez. 1968.

de Saúde promovam a criação de instrumentos legais e institucionais para a coordenação efetiva, no normativo e no executivo, das ações curativas e preventivas do Estado, entre si e destas com as organizações para-estatais, autárquicas e autônomas que prestam quaisquer tipos de cuidados de saúde. $\mathrm{O}$ propósito que se persegue é incorporar a atividade médica dessas instituições, incluindo os hospitais, ao resto dos serviços básicos de saúde, em níveis local, intermediário e nacional, visando obter uma progressiva integração dêstes serviços. A medicina preventiva $\mathrm{e}$ a curativa são um todo integral. .".

Foi provàvelmente em obediência a estas recomendações, e ainda por determinação expressa na Constituição de 1967 (Art. 8. ${ }^{\circ}$ inciso XIV), que o Decreto-lei n. ${ }^{\circ} 200$, de 25-2-1967, ao tratar da reforma administrativa, estabeleceu em seu artigo 156 que "a formulação e coordenação da política nacional de saúde, em âmbito nacional e regional, caberá ao Ministério da Saúde".

O Ministério da Saúde, com efeito, divulgou naquele mesmo ano as diretrizes da política nacional de saúde que visam, em linhas gerais, aos seguintes objetivos prioritários:

1. intensificar o combate às doenças transmissíveis;

2. melhorar a produtividade do sistema de proteção e recuperação da saúde; e

3. expandir a rêde de unidades locais de saúde.

O Plano Nacional de Saúde não toma em consideração a experiência acumulada pelos técnicos nacionais e internacionais, refletida nas recomendações da OMS, OPAS e outras organizações internacionais, nem leva em conta as diretrizes da política de saúde, recentemente divulgadas pelo próprio Ministério da Saúde.

O planejamento de saúde deve ser considerado como um processo técnico contínuo e dinâmico. Consiste, essencialmen- te, na análise inteligente e cuidadosa da problemática da saúde dentro do contexto mais amplo dos problemas de desenvolvimento econômico-social, seguida da fixação de diretrizes gerais para o desenvolvimento metódico dos serviços de saúde, de acôrdo com os conhecimentos modernos e as experiências mais recentes, visando a atender às necessidades de saúde da população, até onde o pérmitam os recursos disponíveis.

As finalidades do planejamento, segundo um grupo de peritos da Organização Mundial da Saúde, são, de um modo geral "racionalizar as atividades..., submeter ao cálculo o que antes se deixava ao sabor do acaso, organizar o que não estava organizado e substituir adaptações espontâneas pela intervenção deliberada".

Do exame do Plano Nacional de Saúde, no tocante à metodologia seguida na sua elaboração, sobressaem algumas falhas fundamentais :

1. Uma das condições essenciais do processo de planejamento é a inclusão do total dos elementos que compóem o setor em estudo. A saúde é um todo indivisível. Qualquer atividade no setor, por mais especializada que seja, deve ser considerada como parte integrante de um programa nacional. O Grupo Assessor em Atenção Médica da Organização Panamericana da Saúde, no documento intitulado "Atención Médica - Bases para la formulación de una política continental", aceitou um esquema que define as diversas atividades de saúde sob a forma de uma gama, que vai desde o contrôle do meio (saneamento, habitação, etc.), até a proteção social e-inclui as atividades de proteção da saúde (contrôle de doenças transmissíveis, imunização, etc.), de manutenção da saúde (higiene materno-infantil, higiene mental, nutrição, educação sanitária) e de recuperação da saúde (atenção médica em sentido estrito, assistência hospitalar, ambulatorial, programas específicos de atenção médica para a tuberculose, doenças mentais, etc.). O Plano aparentemente repudia êste conceito 
EDITORIAL - Apreciação do "plano nacional de saúde. Rev. Saúde públ., S. Paulo, 2(2): 95-110, dez. 1968.

unitário de saúde, que é o conceito moderno. Com efeito, embora ostente na primeira página o título de "Plano de Coordenação das Atividades de Proteção e Recuperação da Saúde", trata apenas do sub-setor da assistência médica, propondo normas que deveriam ser precedidas de diretrizes mais gerais, referentes ao setor saúde como um todo. Procura estabelecer uma dicotomia anacrônica entre saúde coletiva e assistência médica, considerando apenas a primeira como uma responsabilidade governamental.

2. O diagnóstico da problemática de saúde é condição preliminar ao estabelecimento de metas prioritárias. Além da apreciação dos dados de mortalidade e de morbidade e da obtenção de indicadores de saúde, uma análise das necessidades e recursos é essencial ao diagnóstico da situação de saúde. Tal análise é de enorme importância para a fixação de prioridades, pôsto que os recursos são sempre inferiores às necessidades e demanda. 0 Plano não cogita de conhecer a problemática de saúde do País e, assim, necessàriamente, não propõe metas a longo ou curto prazo. Parece claro e irretorquível que o objetivo visado se resume na total privatização da assistência médica do País - o que os autores do Plano apresentam como objetivos-meios, mas que na realidade é a única meta final tangível.

3. Um dos conceitos básicos que deve orientar e presidir à elaboração de um plano de saúde é o de integração das ações preventivas, curativas e sociais. No recente relatório do Grupo de Estudo sôbre a Coordenação da Atenção Médica na América Latina, afirma-se que qualquer sistema que pretenda "separar os componentes do setor saúde, deve ser considerado como anacrônico e desligado das realidades do momento presente".

A integração dos serviços de saúde deve realizar-se nos planos técnico e administrativo. No plano técnico, as funções de proteção, manutenção e restauração da saúde devem ser inseparáveis e, portanto, consideradas simultâneamente para efeito de planejamento de programas. No plano administrativo, tem-se como meta a longo prazo a unificação total, administrativa e financeira, de todos os órgãos que prestam serviços de saúde.

O Plano nem mesmo cogita, aparentemente, de buscar a coordenação adminis. trativa, ou seja, a ordenação metódica da u'ilização dos recursos disponíveis nas diversas instituições públicas e privadas que exercem atividades no setor saúde. Esta coordenação, dada a existência de sérios obstáculos à unificação imediata dos serviços, deve ser considerada como meta atual, transitória, a ser atingida a curto ou médio prazo.

\section{2 - ASPETOS ECONOMMICOS}

Para se avaliar a eficiência econômica de um sistema de prestação de serviços, como o proposto pelo Plano Nacional de Saúde, é preciso compará-lo com as tendências gerais da evolução econômica. O progresso econômico, que se mede pela elevação da produtividade do trabalho $\mathrm{e}$ do bem-estar individual e coletivo, tem-se baseado no crescimento da divisão do trabalho, que se aprofunda mediante a multiplicação das especializações e se amplia pela inclusão, nela, de áreas e populações cada vez maiores. Os dois processos são interdependentes: a cada especialização nova tem que corresponder uma ampliação da divisão do trabalho, isto é, um aumento do tamanho do mercado. $\mathrm{O}$ aumento da produtividade pressupõe, em geral, inovação tecnológica, que requer unidades maiores de produção que, por sua vez, exigem mercados mais amplos.

Os serviços de saúde não têm escapado a esta tendência. Seu avanço tecnológico notável das últimas décadas tem-se alicerçado em equipes médicas e sanitárias cada vez mais amplas, que utilizam equipamentos cada vez mais caros e complexos. $\mathrm{Na}$ medida em que avança a especialização médica, odontológica, etc., é preciso que cresça o número de pessoas 
EDITORIAL - Apreciação do "plano nacional de saúde. Rev. Saúde públ., S. Paulo, 2(2): 95-110, dez. 1968.

atendidas pela respetiva equipe médica, de modo que o custo unitário do serviço não se torne exorbitante. Se se admite, por exemplo, que um "médico trabalhando isoladamente pode atender uma população de 1.000 pessoas, uma equipe de 40 médicos deve poder atender uma população bem maior que de 40.000 pessoas, apresentando ainda serviço qualitativamente superior. Do mesmo modo, um hospital regional de grande porte não é apenas o equivalente à reunião de um número maior de pequenos hospitais, mas uma unidade capaz de atender a um maior número de pessoas devido a um melhor aproveitamento de sua capacidade em leitos, além de poder oferecer um atendimento de melhor nível.

Um sistema de saúde econômicamente eficiente seria, portanto, aquêle que permitisse o melhor uso de unidades altamente especializadas, capazes de atender parcelas cada vez maiores da população. O sistema deveria ser flexível, de modo a ter a máxima permeabilidade à inovação tecnológica. Dentro dêle, a mobilidade de recursos deveria ser muito grande, obedecendo sua distribuição a um planejamento cuidadoso e constantemente revisto, face às mudanças técnicas e sociais apresentadas pela realidade nacional. Qualquer esquema rígido de distribuição de recursos tende a levar à sub-utilização, sendo êste efeito ainda agravado pela pulverização dos elementos humanos e materiais com que se pode contar.

Do ponto de vista econômico, o Plano Nacional de Saúde apresenta a divisão do País em 107 Áreas de Saúde, cada uma contendo um número diferente de habitantes, que varia desde menos de 100.000, como a Área de Corumbá, por exemplo, até quase 7 milhões na Grande São Paulo. Os recursos destinados à saúde serão repartidos por estas 107 Áreas de Saúde, em proporção à renda per capita e à população de cada uma.

Pode-se observar, desde já, que êstes critérios, que dão um pêso de $2 / 3$ à renda per capita e de $1 / 3$ à população, além de arbitrários, tendem a perpetuar a desigualdade regional, que hoje se registra nos padrões de vida da população brasileira, pôsto que favorecem as áreas mais desenvolvidas em detrimento das mais pobres. Considera, por exemplo, o Plano Nacional de Saúde, que a Bahia, com 8,45\% da população do País, deve possuir apenas $4,84 \%$ dos médicos, ao passo que a Guanabara, que tem apenas $4,65 \%$ da população brasileira, deve possuir $11,12 \%$ dos médicos.

Igualmente grave, no entanto, é que a maior virtude que o Plano se arroga, que seria a de elevar a produtividade do serviço de saúde mediante sua privatização, constitui de fato seu maior defeito, pois impõe uma rígida repartição espacial dos recursos destinados à saúde, sem permitir sua concentração, sòmente mediante a qual, significativos ganhos de escala são possíveis. $\mathrm{O}$ avanço tecnológico da medicina tem levado, como nos demais campos da atividade humana, a uma crescente especialização, acompanhada de investimentos cada vez maiores em equipamentos e instalações. Hoje, cada um dos males que afetam o homem é tratado por um número sempre maior de especialistas diferentes, que colaboram entre si, formando equipes cada vez mais numerosas e mais bem aparelhadas. Em conseqüência, a produtividade dessas èquipes de' especialistas e do seu caríssimo instrumental, será proporcional ao número de pessoas que serão atendidas. A tendência, já hoje predominante, e que, tudo leva a crer, só pode se acentuar no faturo, é a formação de hospitais e centros médicos regionais que, à medida que se especializam, só poderão ser rentáveis se a população que atendem fôr também maior. A difusão de recursos por 107 Áreas de Saúde, em que cada paciente "subvencionado" só pode ser atendido em sua própria Área, combinada com a privatização integral de tôda a assistência curativa, só pode resultar na dissolução de muitas das equipes médicas especializadas já existentes, e na concentração das demais nas maiores Áreas de Saúde, co- 
EDITORIAL - Apreciação do "plano nacional de saúde. Rev. Saúde públ., S. Paulo, 2(2): 95-110, dez. 1968.

mo as da Grande São Paulo e Guanabara. Em conseqüência, haverá não apenas perda de qualidade da assistência à saúde, mas também um retardo cada vez maior no avanço da tecnologia médica, que será contida por verdadeira camisa-de-fôrça econômica, representada pela compartimentação dos gastos em saúde, imposta pelo Plano.

\section{3 - ASPETOS FINANCEIROS}

$\mathrm{Na}$ verdade, o problema a ser discutido é muito mais amplo do que o da simples determinação de quanto será gasto nas atividades de saúde. Relaciona-se com o encontro de uma composição intersetorial ótima de gastos e com uma distribuição intrasetorial eficiente dos recursos atribuídos ao setor saúde.
A simples comparação com o que se gasta em outras áreas também não constitui um critério necessàriamente válido, desde que os progrä̀nas diferem de país para país e correspondem a situações histórica e socialmente diferentes.

O exame de algumas informações relativas aos gastos em saúde em vários países nos conduz à conclusão de que, implícita ou explìcitamente, foram aí adotadas decisões derivadas de considerações de ordem puramente local.

A Tabela 1 mostra não existir relação evidente entre Renda Nacional e gastos em saúde, Renda Nacional e facilidades sanitárias (número de médicos e de leitos hospitalares), ou entre gastos em saúde e faciliơades sanitárias.

TA B E L A 1

Renda Nacional «per capita», Gastos em Saúde, Número de Médicos e de Leitos Hospitalares em alguns Países (1961 ou anos próximos)

\begin{tabular}{|c|c|c|c|c|c|}
\hline \multirow{2}{*}{ Países } & \multirow{2}{*}{$\begin{array}{c}\text { Renda «per } \\
\text { capita» } \\
\text { US } \$\end{array}$} & \multicolumn{2}{|c|}{$\begin{array}{c}\text { Gastos em Saúde } \\
(\% \text { da R.N.) }\end{array}$} & \multirow{2}{*}{$\begin{array}{l}\text { Médicos } \\
\text { por } 10.000 \\
\text { hab. }\end{array}$} & \multirow{2}{*}{$\begin{array}{c}\text { Leitos Hosp. } \\
\text { por } 10.000 \\
\text { hab. }\end{array}$} \\
\hline & & Totais (1) & Indiretos (2) & & \\
\hline Estados Unidos & 2306 & 6,8 , & 3,6 & 12,9 . & 90,9 \\
\hline Canadá & 1475 & 7,3 & 4,6 & 11,7 & 110,0 \\
\hline Suécia & $1420^{\circ}$ & 5,6 & $4,4^{\prime}$ & 9,98 & 159,1 \\
\hline Austrália & 1236 & 6,0 & 3,7 & 11,2 & 109,2 \\
\hline Reino Unido & 1172 & 4,9 & 4,2 & 11,0 & 105,5 \\
\hline Dinamarca & 1164 & - & - & 12,3 & 91,0 \\
\hline França & 1079 & 5,5 & 4,9 & 11,0 & 133,9 \\
\hline Israel & 1042 & 7,4 & 5,4 & 25,7 . & 73,8 \\
\hline Tchecoslováquia & 920 & $4 ; 0$ & 3,7 & 18,0 & 124,1 \\
\hline Holanda & 885 & 5,5 & 3,7 & 11,2 & 75,7 \\
\hline Venezuela & 547 & - & 4,6 & 7,0 & 49,9 \\
\hline Chile & 541 & 6,8 & 3,0 & 6,0 & 45,8 \\
\hline Costa Rica & 300 & - & 1,3 & 4,5 & 47,4 \\
\hline Iugoslávia & 233 & 5,2 & 4,9 & 7,0 & 49,9 \\
\hline Peru & 218 & - & - & 5,8 & 22,1 \\
\hline Irã & 173 & - & 1,2 & 2,6 & 11,3 \\
\hline Senegal & 153 & - & 3,4 & 0,45 & 10,6 \\
\hline Ceilão & 120 & 4,2 & 2,6 & 2,16 & 30,7 \\
\hline Paquistão & 74 & - & 0,6 & 0,9 & 2,8 \\
\hline
\end{tabular}

(1) Inclui a parcela paga pelo usuário.

(2) Excluida a parcela paga pelo usuário. 
EDITORIAL - Apreciação do "plano nacional de saúde. Rev. Saúde públ., S. Paulo; 2(2): 95-110, dez. 1968.

A forma de financiamento dos gastos em saúde (Tabela 2) também difere substancialmente, conduzindo à conclusão de que não há uma lei geral que reja tal fenômeno.

Do ponto de vista do uso dos recursos previstos pelo Plano Nacional de Saúde, são esperados "investimentos" que somarão NCr\$ 3.880.000,00, representando $4,5 \%$ do P.I.B. e que serão fornecidos, parte pelos usuários - cêrca de $1 / 3$ e o restante pelo setor público. 0 encargo público corresponderia a cêrca de $15 \%$ das despesas federais, estaduais e municipais.

É importante assinalar, de início, que os chamados "investimentos" em saúde, consignados no Plano, nada mais são do que "transferências" de recursos para cobrir gastos típicos de consumo e que têm como objetivo subvencionar o poder de compra de serviços das classes menos favorecidas. Transparece a idéia de que se trata mais de uma "injeção" de numerário a um setor fornecedor de serviços médicos - o setor privado - que, devido a fatôres ligados à estrutura econômico-social, está visìvelmente em crise, por falta de demanda efetiva.
Não é considerada a necessidade real dos serviços de saúde pela população, independente do nível de renda ou outros fatôres.

Além disso, não há uma indicação segura de fontes de recursos para a ampliação da capacidade instalada, e não se cuida da perícia médica nem da assistência médica ao trabalhador incapacitado por doença, atribuições estas que vêm sendo desempenhadas pela Assistência Médica da Previdência Social. $\chi$

\section{4 - ASPETOS ADMINISTRATIVOS}

Um dos mais valiosos instrumentos de análise de estruturas administrativas só recentemente introduzido no Brasil é representado pela técnica de construção de organogramas proposta pelo Grupo Assessor em Organização e Métodos das Nações Unidas.

Em sua essência, a técnica consiste em seguir um eixo funcional de distribuição espacial, no organograma, dos grandes tipos gerais de funções. Assim, o esquema básico para a localização funcional das unidades estruturais seria a seguinte:

T A B E L A 2

Fontes de Financiamento dos Gastos em Saúde de vários Países (1961 ou anos próximos)

\begin{tabular}{|c|c|c|c|c|}
\hline \multirow{2}{*}{ Países } & \multicolumn{3}{|c|}{ Fontes de Financiamento (\%) } & \multirow[b]{2}{*}{ Usuários } \\
\hline & $\begin{array}{c}\text { Govêrno } \\
\text { Geral }\end{array}$ & $\begin{array}{l}\text { Seguro Social } \\
\text { Compulsório }\end{array}$ & $\begin{array}{l}\text { Outras } \\
\text { Agências }\end{array}$ & \\
\hline Estados Unidos & 22,4 & 1,7 & 28,3 & 47,6 \\
\hline Canadá & 18,4 & 29,6 & 15,6 & 36,4 \\
\hline Austrália & 50,9 & 2,3 & 8,2 & 38,5 \\
\hline França & 15,0 & 67,1 & 7,4 & 10,5 \\
\hline Reino Unido & 84,7 & - & 9,6 & 14,4 \\
\hline Holanda & 20,7 & 42,4 & 4,2 & 32,7 \\
\hline Israel & 28,5 & 3,25 & 41,5 & 26,8 \\
\hline Suécia & 66,3 & 12,2 & - & 21,3 \\
\hline Tchecoslováquia & 86,2 & 5,2 & 1,7 & 7,0 \\
\hline Iugoslávia & 9,8 & 76,6 & 7,3 & 6,2 \\
\hline Venezuela & 37,2 & 5,5 & 6,0 & 51,4 \\
\hline Chile & 23,1 & 6,7 & 13,7 & 56,5 \\
\hline Ceilão & 58,2 & 4,1 & - & 37,7 \\
\hline
\end{tabular}


EDITORIAL - Apreciação do "plano nacional de saúde. Rev. Saúde públ., S. Paulo, 2(2): 95-110, dez. 1968.

UNIDADES DE NIVEL SUPERIOR

(Função Determinativa)

(Nivel de Decisão)
ORGAOS DE ADMINISTRAÇÃO, DIRECCAO SUPERIOR

OU DE COMANDO

\begin{tabular}{|c|c|c|c|}
\hline UNIDADES AUXILIARES & 苋 & త్ర UNIDADES ASSESSÔRAS & \\
\hline (Função Assistencial & 茪 & $\begin{array}{l}\text { (Função Assistencial } \\
\text { Assessôra) }\end{array}$ & $\begin{array}{c}\text { ORGAOS } \ll S T A F F » \\
\text { OU DE }\end{array}$ \\
\hline Auxiliar ou Administrativa) & هัه & 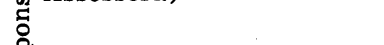 & \\
\hline (Nivel de Serviços Gerais) & 売 & 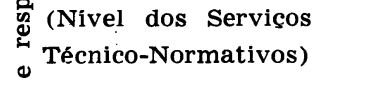 & ESTADU-IMAIUK \\
\hline
\end{tabular}

UNIDADES EXECUTIVAS OU DE OPERAÇA

(Função Aplicativa ou de Execução)

ORGAOS DE LINHA

(Nível dos Serviços de Produção)

Como se pode apreciar, existem quatro grandes espaços funcionais definidos, de forma tal que cada unidade estrutural encontrará sua localização em um dêsses espaços, de acôrdo com seu tipo de função geral.

0 espaço funcional destinado às unidades auxiliares (função assistencial auxiliar ou administrativa) comporta a subdivisão em duas partes: a superior, reservada aos órgãos de estado-maior coordenador (tipo gabinete); e a inferior, onde se situam os chamados órgãos de estado-maior auxiliar, com função essencialmente logística (tipo divisão de administração).

Por sua vez, o espaço funcional ocupado pelas unidades" assessôras (função assistencial assessôra) pode igualmente ser subdividido em duas áreas: a superior, em que se localizam os órgãos de estado. -maior geral, cujo exemplo típico é a unidade de planejamento, e a inferior, destinada aos órgãos de estado-maior técnico (unidades técnico-normativas).

As subdivisões introduzidas no espaço funcional reservado aos órgãos de estado-maior conduzem ao esquema:

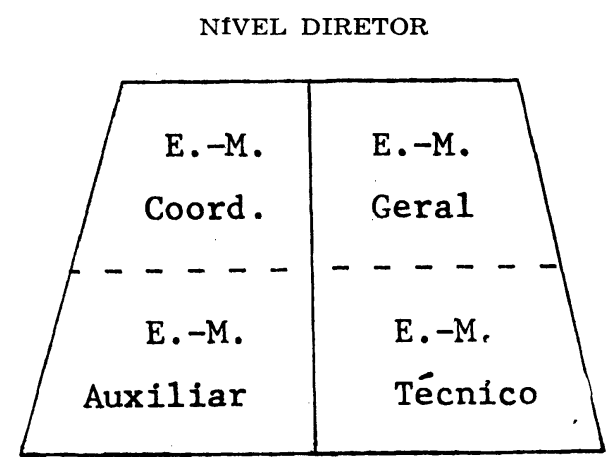

NfVEL EXECUTIVO

As diferencas de nível hierárquico entre as unidades estruturais são fàcilmente caracterizadas, quer pela localização (para as unidades de nível diretor e unidades executivas), quer pelo tamanho diverso dos retângulos e sua localização (no caso dos órgãos de estado-maior).

Como se pode verificar, a técnica é extremamente simples, bastando, para sua correta utilização, definir as atribuições de cada unidade estrutural e situá-la no espaço funcional correspondente do organograma. Sua aplicação ao Plano de Coordenação das Atividades de Proteção e Recuperação da Saúde é objeto das considerações que se seguem. 
EDITORIAL - Apreciação do "plano nacional de saúde. Rev. Saúde públ., S. Paulo, 2(2): 95-110, dez. 1968.

A mais recente versão do citado documento, datada de maio último, relaciona os seguintes órgãos componentes do sistema nacional de saúde:

— um órgão nacional de saúde;

- órgãos estaduais de saúde;

— órgãos locais de saúde, de natureza privada e constituídos com a participação da comunidade;

- profissionais e entidades executoras de serviços, compreendidos nos órgãos locais de saúde.

A estrutura $\mathrm{e}$ as atribuições previstas para êsses órgãos, nos diferentes níveis, são as seguintes:

\section{I - EM Nível NACional}

1. Coordenação Nacional de Assistência Médica, integrante do Ministério da Saúde, com as seguintes funções:

"- sugerir, quando indicada, a revisão da política nacional e das medidas de coordenação das atividades de proteção e recuperação da saúde;

- supervisionar a elaboração dos planos locais de saúde;

- elaborar o orçamento nacional da saúde, visando, especialmente, à compatibilização dos encargos e recursos;

- promover a liberação e o recebimen. to dos recursos destinados ao custeio dos programas de saúde, redistribuindo-os segundo as exigências dos programas em execução; tárias;

- acompanhar as execuções orçamen-

- estabelecer normas específicas relativas aos diversos sistemas de atividades auxiliares de administração;

- proporcionar, nos estados de calamidade ou emergência, recursos médicos para as zonas afetadas;
- promover ou executar as providências necessárias à implantação do sistema nacional de saúde".

2. Conselho Consultivo, presidido pelo dirigente do órgão central, constituído de seis membros, dos quais três designados pelo Ministro da Saúde e os três restantes eleitos, ùm pela Associação Médica Brasileira, um pelas Confederações Nacionais dos Trabalhadores e um pelas Confederações Nacionais das Emprêsas.

$\mathrm{Na}$ qualidade de autoridade máxima do sistema, a Coordenação Nacional de Assistência Médica deverá ocupar, no organograma, o espaço funcional destinado aos órgãos de nível superior, com função determinativa. Assinale-se, contudo, o caráter desconexo de suas atribuições, muitas delas, a rigor, inerentes aos órgãos de estado-maior.

Pela natureza de suas funções, o Conselho Consultivo cuja composição, aliás, assegura maioria de votos ao Ministério da Saúde - estará diretamente ligado à Coordenação Nacional.

\section{II — Em Nível estadual}

1. Junta Estadual de Saúde, constituída de três membros - representando a Secretaria de Saúde do Estado, o Instituto Nacional de Previdência Social e o Ministério da Saúde - sob a presidência do Secretário de Estado ou de representante por êle designado. De acôrdo com o Plano, são as seguintes as atribuições da Junta:

"- propor, quando couber, a revisão dos princípios da política e das medidas de coordenação, a cargo do órgão nacional de saúde;

- pronunciar-se sôbre os planos locais de saúde e controlar sua execução;

- acompanhar a elaboração dos orçamentos das áreas de saúde e elaborar o orçamento estadual do setor; 
EDITORIAL - Apreciação do "plano nacional de saúde. Rev. Saúde públ., S. Paulo, 2(2): 95-110, dez. 1968. rias;

- controlar as execuções orçamentá-

- exercer as funções próprias dos órgãos centrais das atividades auxiliares de administração;

- dirigir a execução local das medidas necessárias à assistência às zonas atingidas, nos estados de calamidade ou emergência;

- dirigir a execução das providências relativas à implantação do sistema nas áreas de saúde do Estado".

2. Comissão Consultiva, presidida por um dos membros da Junta, constituída de seis membros, sendo dois designados pela própria Junta, e os outros quatro eleitos - um, pela entidade estadual filiada à Associação Médica Brasileira, um pela Federação dos Sindicatos Médicos do Estado, um pelas Federações Estaduais dos Trabalhadores e um pelas Federações Estaduais das Emprêsas.

As atribuições previstas para a Junta Estadual não permitem situá-la na linha de autoridade e responsabilidade, pôsto que, além de seu caráter colegiado, êsse órgão não tem, como se verá mais adiante, poderes para exercer qualquer contrôle sôbre as atividades da administração local das áreas de saúde. Impõe-se, assim, sua colocação no espaço funcional reservado aos órgãos de função assistencial auxiliar (estado-maior coordenador ou auxiliar), persistindo," todavia, dúvidas quanto às possibilidades de seu efetivo funcionamento.

A Comissão Consultiva ocupa, em relação à Junta, posição idêntica à estabelecida, no nível nacional, para o Conselho Consultivo.

\section{III - Em Nível Local}

A administração, a coordenação e a fiscalização das atividades locais do sistema nacional de saúde estarão, de acôrdo com o Plano, confiadas a sociedades civis sem finalidade lucrativa, denomina- das Comunidades de Saúde, com sede na cidade da respetiva Área de Saúde, Suas atribuições são de natureza administrativa, financeira, de fiscalização e de orientação.

Deverão ser associados da Comunidade, em caráter obrigatório, os profissionais e entidades integrados na estrutura local do sistema nacional de saúde; e, em caráter facultativo, as seguintes entidades e pessoas :

- municípios compreendidos na Årea de Saúde sob a jurisdição da Comunidade;

- autarquias, emprêsas públicas e sociedades de economia mista que tenham atuação na mesma Área;

- pessoas jurídicas de direito privado, sem fins lucrativos, que sejam consideradas de utilidade pública;

- pessoas físicas que, notória ou comprovadamente, se tenham distinguido por atividades no campo da saúde.

$O$ funcionamento da Comunidade de Saúde, segundo está previsto no documento em estudo, deverá processar-se através de um conjunto de órgãos, a saber:

1. Assembléia Geral, considerado o órgão soberano da Comunidade, congregando todos os associados, na qual o associado pessoa física terá direito a 1 voto e o associado pessoa jurídica, a 3 votos. Compete privativamente à Assembléia Geral:

"_ - eleger e destituir os membros dos Conselhos de Orientação e Fiscal;

- deliberar, com base em parecer do Conselho Fiscal, sôbre o balanço, relatório e prestação de contas, apresentados pela Diretoria Executiva".

2. Conselho de Orientação, composto de seis a dez membros, eleitos pela Assembléia Geral, com mandato de dois anos, sendo, no mínimo, 2 dêles médicos associados obrigatórios, dois representantes dos municípios e dois escolhidos entre pessoas de ilibada reputação que, de pre- 
EDITORIAL - Apreciação do "plano nacional de saúde. Rev. Saúde públ., S. Paulo, 2(2): 95-110, dez. 1968.

ferência, exerçam atividades de natureza assistencial ou econômico-financeira. São funções do Conselho:

" - aprovar o orçamento anual, bem como o programa de trabalho relativo ao exercício;

- angariar recursos supletivos financeiros ou materiais, da coletividade;

- deliberar sôbre as despesas de instalações, de aquisições de material permanente ou de consumo e, também, de adjudicação de serviço, que ultrapassem o limite de 1.000 (mil) salários-mínimos;

- decidir sôbre a aquisição de bens imóveis ou sôbre a alienação de quaisquer bens;

- examinar os balancetes mensais, acompanhando a situação econômica da sociedade;

- propor, justificadamente, ao correspondente Órgão Estadual de Saúde, a substituição de membro da Diretoria Executiva;

- deliberar sôbre a admissão e desligamento de associados, bem como sôbre a aplicação de penalidades;

- suspender a execução de ato ou norma de serviço, expedido pela Diretoria Executiva, quando o considerar contrário aos interêsses sociais, recorrendo, "ex offício" para o Órgão Estadual de Saúde;

- resolver os casos omissos nos Estatutos, "ad referendum" do Órgão Estadual de Saúde; sões".

- expedir o regimento de suas ses-

3. Diretoria Executiva, que deverá ser o órgão responsável pela direção das atividades da sociedade, ressalvadas as que são de competência da Assembléia Geral e do Conselho de Orientação. Essa Diretoria será constituída de:

- 1 Diretor-Superintendente, designado pelo Ministério da Saúde;
- 1 Diretor-Administrativo, designado pelo INPS;

- 1 Diretor-Financeiro, designado pela Secretaria de Saúde do Estado;

- mais 1 ou 2 Diretores, conforme o vulto e complexidade da Área, de indicação municipal.

4. Conselho Fiscal, constituído de três membros e respetivos suplentes, escolhidos pela Assembléia Geral. Será o órgão fiscalizador da gestão econômico-financeira da sociedade, com as atribuições abaixo especificadas:

"- acompanhar a execução orçamentária, conferindo, inclusive, segundo a técnica de amostragem, a classificação contábil dos fatos e examinando sua procedência e exatidão;

- proceder, em face dos documentos de receita e despesa, à verificação periódica dos balancetes;

- examinar a legitimidade dos contratos celebrados;

- pronunciar-se sôbre o processo de prestação de contas, acompanhado do balanço anual, relatório e inventário, apresentados pela Diretoria Executiva;

- requisitar ao Diretor-Superintendente as informações e diligências que julgar necessárias ao bom desempenho de suas atribuições e notificá-lo para a correção de irregularidades acaso encontradas, representando para o Conselho de Orientação, quando desatendido;

- proceder à verificação dos valores e outros bens em depósito na Tesouraria;

- expedir o regimento de suas sessões".

A análise dêsse conjunto de órgãos locais, bem como de suas atribuições e do mecanismo de sua constituição, configura uma situação absolutamente anômala em matéria de estrutura administrativa.

Com efeito:

1. Conquanto declarada soberana, a Assembléia Geral não tem meios de in- 
EDITORIAL" - Apreciação do "plano nacional de saúde. Rev. Saúde públ., S. Paulo, 2(2): 95-110, dez. 1968.

fluir na designação dos componentes da Diretoria Executiva. Cabe-lhe, tão sòmente, a escolha dos membros do Conselho de Orientação e do Conselho Fiscal, órgãos com função predominantemente assistencial auxiliar. Na verdade, e com os inconvenientes de fácil identificação, a composição dêsses dois órgãos se acha sob o contrôle das unidades executoras, na qualidade de membros obrigatórios e mais interessados - da Assembléia Geral. Por outras palavras, os fiscalizados nomeiam seus próprios fiscais.

2. Nos têrmos da estrutura proposta, a linha de mando parte da Coordenação Nacional, passa incólume pelo nível estadual, sem qualquer interferência da Junta respectiva, e chega ao Diretor-Superintendente, que está de fato subordinado diretamente ao órgão ministerial. Daí resulta a marginalização dos órgãos estadual e local, cuja natureza colegiada já representa por si uma limitação ao seu funcionamento normal. As funções de mando previstas para a Junta Estadual e o Conselho de Orientação não encontram, portanto, condições para serem plenamente exercidas.

3. Tal como foi concebida, a estrutura do Plano implica na caracterização de dois sistemas distintos: um primeiro, integrado pelo setor público federal, ao longo do qual fluem os recursos financeiros destinados ao custeio de serviços; e um segundo, totalmente privado, produtor dêsses serviços.

4. Outra séria debilidade da estrutura preconizada no Plano, reside, na quase ausência de órgãos com função assistencial assessôra. Conquanto se mencione que "as atividades de planejamento devem ser exercidas permanentemente", "sendo responsabilidade precípua da chefia" (sic); que se considere tais tarefas como atribuição de profissionais ou técnicos do setor saúde e representantes de entidades de profissionais de classe; e ainda de assessorias de planejamento nos vários níveis, fica-se em dúvida se tais assessorias - incluídas, aliás, no organograma anexo - deverão constituir órgãos formalmente estruturados.

A dúvida decorre do fato de que as atribuições dos "agentes do sistema de planejamento", mencionadas no documento ministerial, denotam lamentável desconhecimento do que hoje se concebe por planejamento. O Plano, em si, é a negação do planejamento, entendido êste como um processo permanente com a função precípua de oferecer, ao nível competente, os elementos necessários à racionalização do processo decisório. Em suma, na vigência de um processo de planejamento, êsse Plano seguramente não teria surgido.

5. Ainda em relação a órgãos com função assistencial assessôra, cabe assinalar a total inexistência de unidades técnico-normativas, destinadas à elaboração de normas técnicas, à fixação de padrões, à determinação de composições instrumentais ótimas, capazes de assegurar maior produtividade à máquina assistencial. $\mathbf{O}$ Plano parte da premissa de que a estrutura ora existente é ineficiente, mas, ao invés de procurar aperfeiçoá-la, simplesmente se propõe a extinguíla.

\section{5 - ASPETOS MEtodológicos}

Os trabalhos versando sôbre o número ideal de médicos para qualquer país mencionam constantemente, como satisfatória, a proporção de um médico para 1.000 habitantes.

Se se meditar sôbre o significado desta relação, concluir-se-á, desde logo, que ela pode satisfazer às condições que permitiram sua fixação, mas não necessàriamente a tôdas as nuanças que exibem os fatôres de demanda de profissionais.

Com efeito, ela pode ser adequada para áreas em que as condições de saúde são de certo tipo, nas quais a população apresenta determinada distribuição e onde os meios que permitem sejam os ser- 
EDITORIAL - Apreciação do "plano nacional de saúde. Rev. Saúde públ., S. Paulo, 2(2): 95-110, dez. 1968.

ORGANOGRAMA DO SISTEMA DE COORDENAÇÃo DAS ATIVIDADES DE PROTEÇAOO

E RECUPERAÇAO DA SAUUDE - 1968

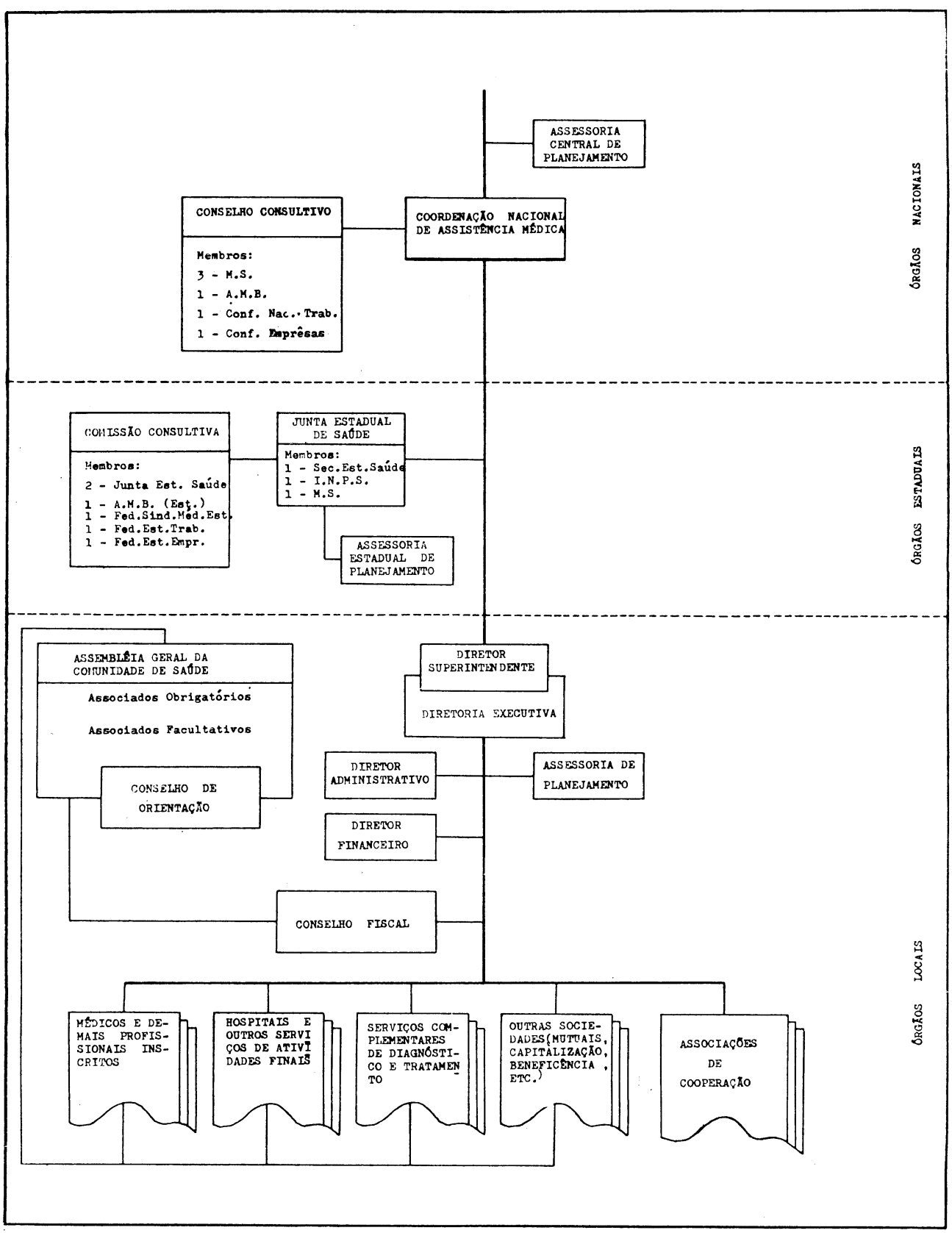

FONTE: Ministério da Saúde - Plano de Coordenação das Atividades de Proteção e Recuperação da Saúde - Maio - 1968. 
EDITORIAL - Apreciação do "plano nacional de saúde. Rev. Saúde públ., S. Paulo, 2(2): 95-110, dez. 1968.

viços médicos alcançados pelos habitantes, têm características conhecidas.

Entretanto, a mesma proporção não pode ser extensiva a zonas onde os agravos à saúde são de outra natureza, em que a densidade populacional é diversa e onde um profissional, frente a peculiaridades geo-econômicas, não pode prestar atendimento ao mesmo número de interessados.

A utilização de uma proporção fixa de médicos em relação ao número de habitantes, ainda que judiciosamente estabelecida, conduz a estimativas errôneas na adequação, se não se levar em conta os quadros nosológicos, a densidade demográfica e as particularidades de cada região.

Com mais forte razão se pode chegar a conclusões destorcidas, quando se parte de proporções reconhecidamente inadequadas.

0 conhecimento dessas verdadeiras necessidades poderia ser obtido através de informações já registradas ou de levantamentos ad hoc. Tais informações seriam representadas essencialmente por indicadores de saúde.

Conquanto se tenha consciência de que a realização simultânea de levantamentos dessa natureza envolve dificuldades consideráveis, devido ao elevado número de itens constantes de uma carta sanitária, êstes são requisitos básicos para qualquer planejamento de saúde.

A análise dos resultados obtidos permitiria definir as variáveis que realmente desempenham papel decisivo na caracterização dos problemas de saúde. Definidas estas, um modêlo ou modelos poderiam ser propostos, numa primeira tentativa de descrever a situação presente. A aferição dêsses modelos em áreas restritas autorizaria ou não sua utilização em escala maior.

Quando se tem em vista as demandas de uma área - em têrmos de especialidades médicas - então o conhecimento das verdadeiras características médico-sanitárias representa etapa fundamental.
De fato, para estabelecer o número de especialistas de tal ou qual ramo de medicina, necessário para esta ou aquela região, outro caminho não existe senão a utilização de indicadores que reflitam a estrutura nosográfica dessa mesma região.

E evidente que, em se tratando de países de dimensões consideráveis, a magnitude da heterogeneidade dos problemas de saúde é apreciável, já que as condições sócio-econômicas tenderão a variar e, com elas, a grandeza daqueles problemas.

Não se pode conceber, portanto, a aplicação apriorística de proporções como a que agora se analisa, porquanto, assim procedendo, não se está respondendo aos reclamos particulares de cada parcela do território em estudo.

No caso do Brasil, país de dimensões continentais, com fisionomia tão diferente conforme a região que se encara, com desniveis sócio-econômicos sobejamente conhecidos e, conseqüentemente, com panoramas médico-sanitários tão díspares, não se poderia esperar que as normas de conduta viessem a ser diferentes.

A simples apreciação dos indicadores disponiveis permite sentir o contraste flagrante entre as condições de saúde das diferentes partes do território nacional (Tabela 3).

Por êstes dados, fica patente que não só as necessidades de médicos devem ser diferentes de uma área para outra, como a quantidade desejável de especialistas dêste ou daquele ramo deve guardar proporção diversa conforme a região.

Se se contrastar a mortalidade por doenças infecto-parasitárias com as produzidas por doenças do aparelho circulatório e neoplasmas, nas diferentes partes do País, as taxas são suficientemente eloqüentes para evidenciar que a problemática é sensìvelmente diversa conforme a área considerada.

Quando se examina o Plano Nacional de Saúde à luz dos comentários feitos anteriormente, nota-se que os elaboradores do documento preferiram, àquele co- 
EDITORIAL - Apreciação do "plano nacional de saúde. Rev. Saúde públ., S. Paulo, 2(2): 95-110, dez. 1968.

T A B E L A 3

Coeficientes de Mortalidade Geral e Especificos, Mortalidade Infantil e Populacão, segundo as Capitais - Período 1963-1966

\begin{tabular}{|c|c|c|c|c|c|c|}
\hline \multirow{2}{*}{ Capitais } & \multicolumn{3}{|c|}{ Coef. de mortal. por 100.000} & \multirow{2}{*}{$\begin{array}{c}\text { Mortal. } \\
\text { Infantil } \\
\text { p/1.000 } \\
\text { nascidos } \\
\text { vivos }\end{array}$} & \multirow{2}{*}{$\begin{array}{c}\text { Mortal. } \\
\text { geral } \\
\text { p/1.000 } \\
\text { habitantes }\end{array}$} & \multirow{2}{*}{$\begin{array}{l}\text { Popula- } \\
\text { ção } \\
\text { em } \\
\text { milhares }\end{array}$} \\
\hline & $\begin{array}{c}\text { Infecc. }+ \\
\text { Parasit. }\end{array}$ & $\begin{array}{l}\text { Neoplas- } \\
\text { mas }\end{array}$ & $\begin{array}{l}\text { Doencas } \\
\text { Aparelho } \\
\text { Circulat. }\end{array}$ & & & \\
\hline Manaus (1966) & 141,8 & 53,8 & 131,5 & 70,2 & 10,1 & 231 \\
\hline Belém (1966) & 135,4 & 59,8 & 93,7 & 139,8 & 8,2 & 522 \\
\hline São Luiz (1964) & 187,2 & 52,6 & 80,3 & 79,1 & 11,8 & 204 \\
\hline Teresina (1966) & 135,4 & 43,8 & 76,2 & 240,6 & 9,6 & 189 \\
\hline Fortaleza (1965) & 115,0 & 30,3 & 134,5 & 166,7 & 15,4 & 745 \\
\hline Natal (1965) & 155,9 & 86,5 & 123,8 & 223,5 & 17,1 & 217 \\
\hline João Pessoa (1966) & 281,5 & 83,4 & 159,1 & 137,3 & 16,6 & 176 \\
\hline Recife (1966) & 174,1 & 75,0 & 167,2 & 149,4 & 13,5 & 1014 \\
\hline Maceió (1966) & 194,6 & 80,7 & 144,7 & 300,5 & 16,2 & 207 \\
\hline Aracajú (1965) & 47,2 & 40,5 & 104,1 & 101,9 & 10,4 & 145 \\
\hline Salvador (1966) & 158,8 & 73,7 & 136,0 & 124,2 & 10,8 & 821 \\
\hline B. Horizonte (1966) & 134,3 & 123,0 & 159,7 & 87,2 & 12,1 & 1022 \\
\hline Vitória (1966) & 172,5 & 142,0 & 192,5 & 124,3 & 18,5 & 115 \\
\hline Niterói $\quad(1966)$ & 108,7 & 105,9 & 228,2 & 110,5 & 10,7 & 288 \\
\hline R. de Janeiro (1962) & 116,7 & 105,3 & 186,2 & 65,3 & 9,8 & 3949 \\
\hline São Paulo (1964) & 60,1 & 105,6 & 163,0 & 67,7 & 8,7 & 5088 \\
\hline Curitiba (1966), & 109,0 & 134,6 & 198,3 & 73,2 & 11,3 & 578 \\
\hline Florianópolis (1965) & 23,9 & 25,6 & 95,4 & 94,9 & 9,6 & 122 \\
\hline Pôrto Alegre (1963) & 138,7 & 128,4 & 129,6 & 100,8 & 10,6 & 848 \\
\hline Cuiabá (1966) & 107,5 & 54,5 & 120,1 & 57,2 & 7,8 & 79 \\
\hline Goiânia (1963) & 175,5 & 56,1 & 228,9 & 51,6 & 11,9 & 276 \\
\hline
\end{tabular}

FONTE: Anuário Estatístico do Brasil, IBGE, 1967. 
EDITORIAL - Apreciação do "plano nacional de saúde. Rev. Saúde públ., S. Paulo, 2(2): 95-110, dez. 1968.

nhecimento básico, raciocinar com algumas pressuposições e com o número atual de médicos disponíveis, o que sugere busquem metas diversas das que deveriam.

Adotando o lema "o que fazer com o que temos", ao invés de "o que fazer para termos o que precisamos", tudo foi planejado conforme o inventário do presente.

Essa tática não pode gerar qualquer solução para as necessidades existentes, simplesmente porque as mesmas necessidades não foram definidas e, por conseguinte, não foram comprovadas.

Admite o Plano Nacional de Saúde quatro categorias sócio-econômicas e, aceitando que a utilização de serviços médicos por estas categorias (A, B, C e D) obedeça a certo padrão $(1,1,1,5$ e 2$)$, aplica indiscriminadamente a tôdas as áreas a proporção calculada sôbre êstes dados, ponderando simplesmente sôbre o total da população e a renda bruta.

Quando se preocupa com os especialistas, o Plano pretende adotar uma proporção única, que é a vigente atualmente no País. Esta, jamais planejada ou mesmo orientada, só casualmente poderia ser adequada.

A distribuição do número de médicos obedeceu ao seguinte modêlo:

$$
\mathrm{Li}=\frac{1}{3} \mathrm{pi}+\frac{2}{3} \mathrm{ri},
$$

onde $p i$ é a proporção da população da área de saúde $i$, em relação à população total do País; ri é a proporção da renda bruta da mesma área em relação à renda bruta do País e $L i$ é a proporção de médicos da área $i$ em relação ao número total de médicos do País. A impropriedade dos pesos $1 / 3$ e $2 / 3$ já foi abordada no estudo dos aspetos econômicos. Como se vê, êste modêlo permite calcular o número de médicos para cada região, isto é:

$$
\mathrm{Mi}=\mathrm{Li} \quad \mathrm{M},
$$

onde $M i$ é o número de médicos para a regiáo $i$ e $M$ o número total de médicos do País.

Por outro lado, a repartição por especialidades observou o número de horas disponíveis, segundo padrão vigente no País. Hora médico e horas disponíveis não são desvinculáveis e a aplicação dêsse critério é impossível, a menos que os profissionais possuam o dom da ubiqüidade. Acresce lembrar que o número de horas disponíveis não é apenas função do número de médicos, mas também de outras variáveis, como as condições geo-econômicas, densidade demográfica, etc.

\section{CONCLUSOES}

A implantação do Plano Nacional de Saúde implicará:

1. no agravamento da injustificável e absoleta dicotomia entre as atividades de medicina preventiva e curativa;

2. na eliminação de estruturas estatais de saúde, cuja privatização para fins puramente assistenciais exclui a possibilidade de sua utilização com finalidade também preventiva;

3. no estabelecimento de uma estrutura especìficamente destinada a canalizar recursos do setor público para o privado, êste fiscalizado pelos próprios executores do serviço;

4. numa tentativa de fortalecer o setor privado, visivelmente em crise devido a fatôres ligados à estrutura sócio-econômica do País;

5. no desvio, para tôda a população, de fundos da Previdência Social que, de direito, pertencem apenas a empregado e empregador;

6. no retardo cada vez maior do avanço da tecnologia médica, que será 
EDITORIAL - Apreciação do "plano nacional de saúde. Rev. Saúde públ., S. Paulo, 2(2): 95-110, dez. 1968.

contida por verdadeira camisa-de-fôrça econômica, representada pela compartimentação de gastos em saúde;

7. na dissolução de muitas das equipes médicas especializadas já existentes e na concentração das demais nas Áreas de Saúde maiores;

8. no surgimento de grupos indevidamente privilegiados não sòmente entre os segurados como entre os fornecedores de serviços;

9. na perpetuação da desigualdade regional que hoje se registra nos padrões de vida da população brasileira, pôsto que favorece as áreas mais desenvolvidas, em detrimento das mais pobres;

10. em nítida colisão dentro de suas próprias normas. 